\title{
Morphology Effect on the Kinetic Parameters and Surface Thermodynamic Properties of $\mathbf{A g}_{3} \mathbf{P O}_{4}$ Micro-/Nanocrystals
}

\author{
Zai-Yin Huang, ${ }^{1,2,3,4}$ Xing-Xing Li, ${ }^{2}$ Zuo-Jiao Liu, ${ }^{2}$ Liang-Ming He, ${ }^{2}$ and Xue-Cai Tan ${ }^{2,3,4}$ \\ ${ }^{1}$ Chemical and Environmental Engineering, Baise University, Baise 533000, China \\ ${ }^{2}$ College of Chemistry and Chemical Engineering, Guangxi University for Nationalities, Nanning 530008, China \\ ${ }^{3}$ Key Laboratory of Forest Chemistry and Engineering, Guangxi University for Nationalities, Nanning 530008, China \\ ${ }^{4}$ Guangxi Colleges and Universities Key Laboratory of Food Safety and Pharmaceutical Analytical Chemistry, \\ Guangxi University for Nationalities, Nanning 530008, China
}

Correspondence should be addressed to Zai-Yin Huang; huangzaiyin@163.com

Received 28 April 2015; Accepted 1 October 2015

Academic Editor: Yu-Lun Chueh

Copyright (c) 2015 Zai-Yin Huang et al. This is an open access article distributed under the Creative Commons Attribution License, which permits unrestricted use, distribution, and reproduction in any medium, provided the original work is properly cited.

Considerable effort has been exerted using theoretical calculations to determine solid surface energies. Nanomaterials with high surface energy depending on morphology and size exhibit enhanced reactivity. Thus, investigating the effects of morphology, size, and nanostructure on the surface energies and kinetics of nanomaterials is important. This study determined the surface energies of silver phosphate $\left(\mathrm{Ag}_{3} \mathrm{PO}_{4}\right)$ micro-/nanocrystals and their kinetic parameters when reacting with $\mathrm{HNO}_{3}$ by using microcalorimetry. This study also discussed rationally combined thermochemical cycle, transition state theory, basic theory of chemical thermodynamics with thermokinetic principle, morphology dependence of reaction kinetics, and surface thermodynamic properties. Results show that the molar surface enthalpy, molar surface entropy, molar surface Gibbs free energy, and molar surface energy of cubic $\mathrm{Ag}_{3} \mathrm{PO}_{4}$ micro-/nanocrystals are larger than those of rhombic dodecahedral $\mathrm{Ag}_{3} \mathrm{PO}_{4}$ micro-/nanocrystals. Compared with rhombic dodecahedral $\mathrm{Ag}_{3} \mathrm{PO}_{4}$, cubic $\mathrm{Ag}_{3} \mathrm{PO}_{4}$ with high surface energy exhibits higher reaction rate and lower activation energy, activation Gibbs free energy, activation enthalpy, and activation entropy. These results indicate that cubic $\mathrm{Ag}_{3} \mathrm{PO}_{4}$ micro-/nanocrystals can overcome small energy barrier faster than rhombic dodecahedral $\mathrm{Ag}_{3} \mathrm{PO}_{4}$ micro-/nanocrystals and thus require lower activation energy.

\section{Introduction}

Nanomaterials that exhibit high specific surface effect differ from massive materials in terms of physical and chemical properties [1, 2]. Du et al. [3] explained that the specific surface effect, surface heat capacity, and specific surface energy of nanomaterials cannot be neglected. The overall thermodynamic property of nanoparticles comprises surface and bulk phases [3-9]. Surface thermodynamic properties are the intuitive expression of the special structure-activity relationship of nanomaterial surface, which significantly affects many physical/chemical reactions, including chemical thermodynamics $[3,4]$, chemical kinetics [5], catalysis [1013], sense [11], adsorption [14], phase transition [15], and electrochemistry of nanomaterials [16]. Theoretical calculation results showed that nanomaterials with different sizes and facets have different surface energies [17-19] and that the reactivity of nanomaterials depends on surface energy [11, 12]. Studying the surface thermodynamic property of nanomaterials and the structure-function relationship between reaction dynamics and size, morphology, and structure is valuable to understand the nature of chemical reactions.

Calorimetry [7, 8, 20, 21], contact angle [22], Young modulus $[23,24]$, balance crystal shape $[3,25]$, zero creep, and field-emission microscopic method [26] are common methods of measuring solid surface energy. Hulett $[27,28]$ reported that the surface energies of $\mathrm{BaSO}_{4}$ and $\mathrm{CaSO}_{4} \cdot 2 \mathrm{H}_{2} \mathrm{O}$ obtained using the Ostwald-Freundlich formula are within 1000-3000 $\mathrm{mJ} \cdot \mathrm{m}^{-1}$. However, Tang et al. [29-32] discovered that results obtained using the Ostwald-Freundlich formula for nanoparticles with far higher solubility than common crystals contradict with experimental facts. Thus, Tang et al. 
$[31,32]$ measured the surface energy of inorganic insoluble salt indirectly through crystal growth or dissolution kinetics. Methods commonly used in Young modulus (e.g., tearing) and other methods involving compression, solubilization, high-temperature dissolution, or lowering of melting point produce high and even applied stress-covered surface energies. Hence, theoretical calculation is preferred to measure solid surface energy [23]. Nevertheless, theoretical calculation often deviates from the practical ideal model and from many hypotheses. Real surfaces with abundant atom ladders and unsaturated bonds, as well as those with unstable thermodynamics, tend to absorb water [7], gas molecules, and surfactant [11, 12]; undergo surface atom reconstruction and aggregation; or even form a protective film layer. The surface energies of these complicated real surfaces are extremely difficult to theoretically calculate. Experimental measurement still faces several challenges. Different experimental methods provide significantly different values for the surface energies of the same material [33]; researchers using the same experimental method also obtain varying results $[34,35]$. A universal method to determine surface energy has yet to be developed. Developing a scientific and universal experimental method to measure the surface energy of nanomaterials is a pressing need in the scientific endeavors on solid surface and in other disciplines.

The visible-light-driven $\mathrm{Ag}_{3} \mathrm{PO}_{4}$ photocatalyst has become popular since its introduction in 2010 [36, 37]. Scientists calculated the surface energies of different facets of $\mathrm{Ag}_{3} \mathrm{PO}_{4}$ on the basis of the relationship between included angle of crystal faces and Miller index [38]. Other researchers performed the same calculation by using density functional theory [39]. Studying the structure-function relationship between the surface energy of micro-/nanomaterial $\mathrm{Ag}_{3} \mathrm{PO}_{4}$ and size, morphology, and structure is valuable to understand the natures of chemical reactions. However, the surface energy of this material was rarely calculated using experimental methods. The present study determined the surface energies of $\mathrm{Ag}_{3} \mathrm{PO}_{4}$ micro-/nanocrystals with cubic and rhombic dodecahedral morphologies and their kinetic parameters when reacting with $\mathrm{HNO}_{3}$ by using microcalorimetry. This study also discussed rationally combined thermochemical cycle, transition state theory, basic theory of chemical thermodynamics with thermokinetic principle, morphology dependence of reaction kinetics, and surface thermodynamic properties.

\section{Experiments}

2.1. Materials. Analytical-grade sodium dihydrogen phosphate dihydrate $\left(\mathrm{NaH}_{2} \mathrm{PO}_{4} \cdot 2 \mathrm{H}_{2} \mathrm{O}\right)$, disodium phosphate dodecahydrate $\left(\mathrm{NaH}_{2} \mathrm{PO}_{4} \cdot 12 \mathrm{H}_{2} \mathrm{O}\right)$, silver nitrate $\left(\mathrm{AgNO}_{3}\right)$, ammonium hydroxide $\left(\mathrm{NH}_{3} \cdot \mathrm{H}_{2} \mathrm{O}\right)$, potassium chloride $(\mathrm{KCl})$, and nitric acid were purchased from Sinopharm Chemical Reagent Co. Ltd. and used without further purification. Deionized water with a resistivity of $18.2 \mathrm{M} \Omega \cdot \mathrm{cm}$ was used in all experiments.

2.2. Characterization. The morphology of the sample was examined under a field-emission scanning electron microscope (Zeiss SUPRA 55 Sapphire, Germany). The X-ray diffraction (XRD) pattern was recorded on an X-ray powder diffractometer (Philips PW 1710 with $\mathrm{Cu} \mathrm{K} \alpha$ radiation, $\lambda=$ $1.5406 \AA$, Holland). Trace amounts of the sample were measured on a XPE analytic balance (Mettler Toledo, Switzerland). Calorimetric experiments were performed using a microcalorimeter (RD496L, Mianyang CP Thermal Analysis Instrument Co., Ltd., China) under constant temperature and pressure.

2.3. Calorimetric Experiment. Rhombic dodecahedrons, cubes, and bulk $\mathrm{Ag}_{3} \mathrm{PO}_{4}$ were prepared by a simple ion-exchange method at room temperature [40]. The microcalorimeter was calibrated by Joule effect, and its calorimetric constant was $(69.91 \pm 0.56) \mu \mathrm{V} \cdot \mathrm{mW}^{-1}$ at $298.15 \mathrm{~K}$. The dissolution enthalpy of $\mathrm{KCl}$ in deionized water $\left(1: 1110, m_{\mathrm{KCl}} / m_{\text {de-water }}\right)$ was $(17.792 \pm 0.029) \mathrm{kJ} \cdot \mathrm{mol}^{-1}$. This value agrees with the previously published value of $(17.524 \pm 0.028)$ [41]. This agreement indicates that the calorimetric system is accurate and reliable.

A small glass tube containing $1.0 \mathrm{~mL}$ of $0.36 \mathrm{M} \mathrm{HNO}_{3}$ solution was placed above a $15 \mathrm{~mL}$ glass tube charged with $1.500 \mathrm{mg}$ of $\mathrm{Ag}_{3} \mathrm{PO}_{4}$ samples (bulk or the obtained nanocubes). Simultaneously with the establishment of equilibrium, the small glass tube with $\mathrm{HNO}_{3}$ solution was pushed down. The in situ thermodynamic and kinetic information for this reaction was recorded using the microcalorimeter.

2.4. Establishment of Chemical Reaction Kinetic Models for Cubic and Rhombic Dodecahedron $\mathrm{Ag}_{3} \mathrm{PO}_{4}$ Micro-/Nanocrystals. The specific surface area and specific surface energy of the reactant increase after being refined; thus, the mean molar energy of the refined reactant is higher than that of the corresponding bulk reactant. If the reactant particle size is insignificant to the mean energy of the activated molecules, then the difference between the mean molecular activation energy of $1 \mathrm{M}$ of nanoparticles and mean energy of $1 \mathrm{~mol}$ super-refined reactant is the chemical activation energy of the nanomaterial [42]. Figure 1 shows the transition state theory $[8,42,43]$. In the same chemical reaction, the reactant experiences the same transition state to the final state. Therefore, the apparent activation energy of nanoparticles $E_{a}$ is the difference between the activation energy of corresponding bulk material $\left[E_{a}\right.$ (bulk)] and the molar surface energy of nanoparticles $\left(E_{m}^{S}\right)$ :

$$
E_{a}(\text { nano })=E_{a}(\text { bulk })-E_{m}^{S} .
$$

If the dispersion phase in heterogeneous reaction has only one reactant and others belong to the continuous phase, then the relationship between surface energy and apparent activation energy for cubic nanoparticles without inner bores can be expressed as

$$
E_{a}(\text { nano })=E_{a}(\text { bulk })-E_{m}^{S}=E_{a}(\text { bulk })-\frac{4 \sigma M}{\rho l},
$$

where $\sigma, M, \rho$, and $l$ are the surface tension, molar mass, density, and particle size (length of cube edge) of the cubic nanoparticle reactant, respectively. Equation (2) provides that the apparent activation energy in the chemical reaction of the nanomaterials is proportional to the particle size of the reactant. 


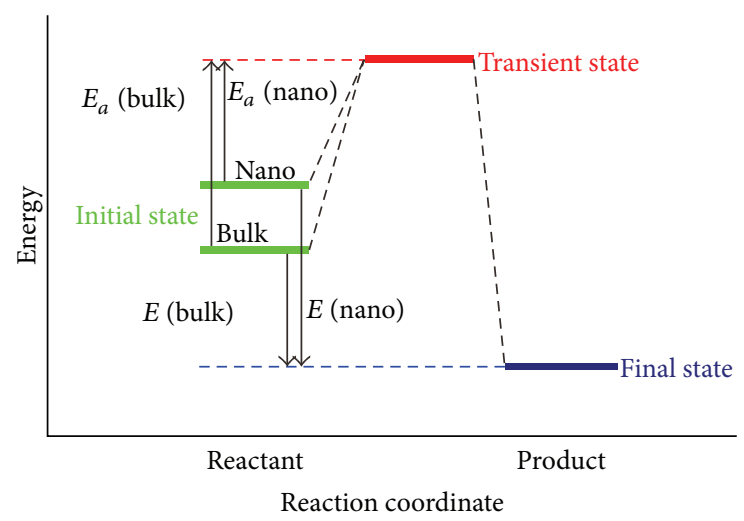

FIGURE 1: Schematic of relationship between surface energy and apparent activation energy.

If the heterogeneous reaction follows Arrhenius Law, substituting (2) into it yields the Arrhenius equation of the nanocube:

$$
k=A \exp \left[-\frac{E_{a}^{b}}{R T}+\frac{4 \sigma M}{R T \rho l}\right]
$$

Similarly, the Arrhenius equation of dodecahedron is obtained:

$$
k=A \exp \left[-\frac{E_{a}^{b}}{R T}+\frac{\sqrt{6} \sigma M}{R T \rho l}\right]
$$

where $T$ is the reaction temperature, $k$ is the reaction rate constant, and $A$ is the preexponential factor.

Substituting the logarithm on both sides of (4), we obtain the following:

Cube:

$$
\ln k=\ln A-\frac{E_{a}^{b}}{R T}+\frac{4 \sigma M}{\rho l} .
$$

Dodecahedron:

$$
\ln k=\ln A-\frac{E_{a}^{b}}{R T}+\frac{\sqrt{6} \sigma M}{\rho l} .
$$

Therefore, when the particle size is larger than $10 \mathrm{~nm}$, the surface tension slightly changes and can be viewed as a constant [43]. On the basis of (5) and (6), the logarithm of the reaction rate constant is inversely proportional to the particle size of the reactant.

2.5. Acquisition of Dynamic Parameters of $\mathrm{Ag}_{3} \mathrm{PO}_{4}$ Reacting with $\mathrm{HNO}_{3}$. The thermodynamic equation of reversible chemical reaction under constant temperature and pressure can be expressed as [44]

$$
\ln \left[\frac{1}{H_{\infty}} \frac{\mathrm{d} H_{i}}{\mathrm{~d} t}\right]=\ln k+n \ln \left[1-\frac{H_{i}}{H_{\infty}}\right]
$$

where $H_{\infty}$ is the enthalpy change during the whole reaction and may be directly obtained by microcalorimetry, $\mathrm{d} H_{i} / \mathrm{d} t$ is the enthalpy change rate, $k\left(\mathrm{~s}^{-1}\right)$ is the reaction rate constant expressed by conversion rate, and $H_{i}$ is the enthalpy change at reaction time $t$. $k$ can be calculated from the linear regression of thermodynamic data:

$$
\begin{aligned}
\ln k & =\ln A-\frac{E_{a}}{R T} \\
\Delta G_{\neq}^{\theta} & =R T \ln \left[\frac{R T}{N_{A} h k}\right] \\
\ln \frac{k}{T} & =\ln \frac{k_{B}}{h}+\frac{\Delta S_{\neq}^{\theta}}{R}-\frac{\Delta H_{\neq}^{\theta}}{R T},
\end{aligned}
$$

where $N_{A}$ is Avogadro's constant, $k_{B}$ is Boltzmann's constant, $h$ is Planck's constant, and $R$ is the molar gas constant. The diagram of $1 / T$ was drawn with $\ln k . E_{a}$ and $A$ were calculated using (8). $\Delta G_{\neq}^{\theta}, \Delta H_{\neq}^{\theta}$, and $\Delta S_{\neq}^{\theta}$ were calculated from (9) and (10).

2.6. Theoretical Derivation of Molar Surface Gibbs Free Energy, Molar Surface Enthalpy, Molar Surface Entropy, and Molar Surface Energy. The molar Gibbs free energy of chemical reaction of nanosystem consists of bulk phase $\left(\Delta_{r} G_{m}^{B}\right)$ and surface phase $\left(\Delta_{r} G_{m}^{S}\right)[8,42]$ :

$$
\Delta_{r} G_{m}(\text { nano })=\Delta_{r} G_{m}^{B}+\Delta_{r} G_{m}^{S} .
$$

The molar Gibbs free energy of the bulk chemical reaction nearly exhibits bulk phase. The bulk phase of the nanosystem is similar to that of bulk:

$$
\Delta_{r} G_{m}^{B}=\Delta_{r} G_{m} \text { (bulk), }
$$

where $\Delta_{r} G_{m}$ (bulk) is the molar Gibbs free energy of the same chemical reaction bulk material.

Therefore, the molar Gibbs free energy difference between the nanosystem and the bulk lies in the molar surface Gibbs free energy of the nanomaterial (excessive Gibbs free energy compared with bulk material). Substituting (12) into (11), we obtain

$$
\Delta_{r} G_{m}^{S}=\Delta_{r} G_{m} \text { (nano) }-\Delta_{r} G_{m} \text { (bulk). }
$$

On the basis of (13), the thermochemical cycles of nanoand bulk $\mathrm{Ag}_{3} \mathrm{PO}_{4}$ were designed (Figure 2). The thermodynamic functions of nano- and bulk $\mathrm{Ag}_{3} \mathrm{PO}_{4}$ reactions with $\mathrm{HNO}_{3}$ were tested. The thermodynamic function of nano$\mathrm{Ag}_{3} \mathrm{PO}_{4}$ conversion into the bulk one was calculated on the basis of their difference.

On the basis of (12), the chemical reaction for the molar surface Gibbs of $\mathrm{Ag}_{3} \mathrm{PO}_{4}$ micro-/nanocrystals with a net reaction of $\mathrm{Ag}_{3} \mathrm{PO}_{4}$ (nano) $\rightarrow \mathrm{Ag}_{3} \mathrm{PO}_{4}$ (bulk) is

$$
\begin{aligned}
\Delta_{r} G_{m}^{\theta}= & \Delta_{r} G_{m}^{\theta}\left(\mathrm{Ag}_{3} \mathrm{PO}_{4}, \text { nano }\right) \\
& -\Delta_{r} G_{m}^{\theta}\left(\mathrm{Ag}_{3} \mathrm{PO}_{4}, \text { bulk }\right) \\
= & \Delta_{r} G_{m}^{S}\left(\mathrm{Ag}_{3} \mathrm{PO}_{4}, \text { nano }\right) \\
= & -G_{m}^{S}\left(\mathrm{Ag}_{3} \mathrm{PO}_{4}, \text { nano }\right)
\end{aligned}
$$




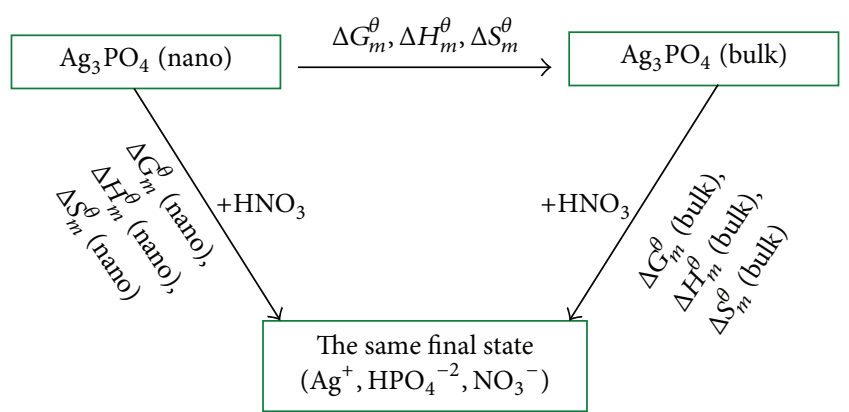

Figure 2: Thermochemical cycle of nano- and bulk $\mathrm{Ag}_{3} \mathrm{PO}_{4}$ reacting with $\mathrm{HNO}_{3}$.

where $\Delta G_{m}^{\theta}\left(\mathrm{Ag}_{3} \mathrm{PO}_{4}\right.$, nano $)$ and $\Delta G_{m}^{\theta}\left(\mathrm{Ag}_{3} \mathrm{PO}_{4}\right.$, bulk $)$ are the standard molar Gibbs free energies of the reactions of $\mathrm{Ag}_{3} \mathrm{PO}_{4}$ micro-/nanocrystals and bulk $\mathrm{Ag}_{3} \mathrm{PO}_{4}$ with $\mathrm{HNO}_{3}$, respectively; $\Delta G_{m}^{S}\left(\mathrm{Ag}_{3} \mathrm{PO}_{4}\right.$, nano $)$ and $G_{m}^{S}\left(\mathrm{Ag}_{3} \mathrm{PO}_{4}\right.$, nano $)$ are the molar reaction surface Gibbs free energy and molar surface Gibbs free energy, respectively.

In accordance with transition state theory, the relationship between reaction rate constants of $\mathrm{Ag}_{3} \mathrm{PO}_{4}$ micro-/ nanocrystals reaction system and bulk $\mathrm{Ag}_{3} \mathrm{PO}_{4}$ reaction system and the Gibbs free energy can be expressed as $[8,45]$

$$
\begin{aligned}
& \Delta_{r} G_{m}^{\theta}\left(\mathrm{Ag}_{3} \mathrm{PO}_{4}, \text { nano }\right)-\Delta_{r} G_{m}^{\theta}\left(\mathrm{Ag}_{3} \mathrm{PO}_{4}, \text { bulk }\right) \\
& \quad=\Delta_{r} G_{\neq}^{\theta}(\text { bulk })-\Delta_{r} G_{\neq}^{\theta}(\text { nano }) \\
& \quad=R T\left(\ln k_{\text {bulk }}-\ln k_{\text {nano }}\right),
\end{aligned}
$$

where $\Delta_{r} G_{\neq}^{\theta}$ and $k$ are the activation Gibbs free energy and rate constant of $\mathrm{Ag}_{3} \mathrm{PO}_{4}$ chemical reaction.

On the basis of (14) and (15),

$$
\begin{aligned}
G_{m}^{S}\left(\mathrm{Ag}_{3} \mathrm{PO}_{4}, \text { nano }\right) & =-\Delta_{r} G_{m}^{S}\left(\mathrm{Ag}_{3} \mathrm{PO}_{4}, \text { nano }\right) \\
& =-R T\left(\ln k_{\text {bulk }}-\ln k_{\text {nano }}\right) .
\end{aligned}
$$

Similarly, $\Delta H_{\neq}^{\theta}$ can be calculated from (10). Molar surface enthalpy can be deduced from transition state theory:

$$
\begin{aligned}
\Delta_{r} H_{m}^{S} & =\Delta_{r} H_{m}^{\theta}(\text { nano })-\Delta_{r} H_{m}^{\theta} \text { (bulk) } \\
& \left.=\Delta_{r} H_{\neq}^{\theta}(\text { bulk })-\Delta_{r} H_{\neq}^{\theta} \text { (nano }\right) \\
\Delta_{r} H_{m}^{S} & =H_{m}\left(\mathrm{Ag}_{3} \mathrm{PO}_{4}, \text { nano }\right)-H_{m}\left(\mathrm{Ag}_{3} \mathrm{PO}_{4}, \text { bulk }\right) \\
& =-H_{m}^{S}\left(\mathrm{Ag}_{3} \mathrm{PO}_{4}\right),
\end{aligned}
$$

where $\Delta_{r} H_{m}^{S}, \Delta_{r} H_{m}^{\theta}, \Delta_{r} H_{\neq}^{\theta}$, and $H_{m}^{S}$ are the molar surface reaction enthalpy, molar reaction enthalpy, molar activation enthalpy, and molar surface enthalpy of $\mathrm{Ag}_{3} \mathrm{PO}_{4}$ chemical reaction, respectively.
Similarly, molar surface entropy can be deduced from transition state theory:

$$
\begin{aligned}
\Delta_{r} S_{m}^{S} & =\Delta_{r} S_{m}^{\theta} \text { (nano) }-\Delta_{r} S_{m}^{\theta} \text { (bulk) } \\
& =\Delta_{r} S_{\neq}^{\theta} \text { (bulk) }-\Delta_{r} S_{\neq}^{\theta} \text { (nano) } \\
\Delta_{r} S_{m}^{S} & =S_{m}\left(\mathrm{Ag}_{3} \mathrm{PO}_{4}, \text { nano }\right)-S_{m}\left(\mathrm{Ag}_{3} \mathrm{PO}_{4}, \text { bulk }\right) \\
& =-S_{m}^{S}\left(\mathrm{Ag}_{3} \mathrm{PO}_{4}\right),
\end{aligned}
$$

where $\Delta_{r} S_{m}^{S}, \Delta_{r} S_{m}^{\theta}, \Delta_{r} S_{\neq}^{\theta}$, and $S_{m}^{S}$ are the molar surface reaction entropy, molar reaction entropy, molar activation entropy, and molar surface entropy of $\mathrm{Ag}_{3} \mathrm{PO}_{4}$ chemical reaction, respectively.

Apparent activation energy refers to the total energy needed for the material to overcome activation. The essential difference between $\mathrm{Ag}_{3} \mathrm{PO}_{4}$ micro-/nanocrystals and bulk $\mathrm{Ag}_{3} \mathrm{PO}_{4}$ is the high specific surface effect of the surface phase. After the same transition state to the final state in the same chemical reaction (Figure 1), the surface energy of the nanosystem surface phase $\left(E_{m}^{S}\right)$ is the energy difference between the nano-reaction system and the bulk reaction system. The molar surface energy in the manuscript cited reference [8] which deduced in our published paper. Its correct form is [8]. Consider

$$
\begin{aligned}
\Delta E_{m}^{S} & =E(\text { nano })-E(\text { bulk })=E_{a}(\text { bulk })-E_{a}(\text { nano }) \\
\Delta_{r} E_{m}^{S} & =E_{m}\left(\mathrm{Ag}_{3} \mathrm{PO}_{4}, \text { nano }\right)-E_{m}\left(\mathrm{Ag}_{3} \mathrm{PO}_{4}, \text { bulk }\right) \\
& =-E_{m}^{S}\left(\mathrm{Ag}_{3} \mathrm{PO}_{4}\right),
\end{aligned}
$$

where $\Delta E_{m}^{S}, E_{a}$, and $E_{m}$ are the molar surface reaction energy, activation energy, and molar surface energy of $\mathrm{Ag}_{3} \mathrm{PO}_{4}$ chemical reaction, respectively.

\section{Results and Discussion}

3.1. Product Characterization. Figures $3(\mathrm{a})-3(\mathrm{c})$ show the SEM images of $\mathrm{Ag}_{3} \mathrm{PO}_{4}$ micro-/nanocrystals. Cubic $\mathrm{Ag}_{3} \mathrm{PO}_{4}$ has six (100) faces, clear and sharp edges and angles, and smooth surfaces; the mean particle size is $(695.9 \pm 100.2) \mathrm{nm}$. Figure 3(b) is the rhombic dodecahedral $\mathrm{Ag}_{3} \mathrm{PO}_{4}$ with 12 rhombus (110) faces. White spots are scattered on the surfaces; the mean particle size is $(647.1 \pm 91.8) \mathrm{nm}$. Figure 3(c) shows the SEM image of the irregularly shaped $\mathrm{Ag}_{3} \mathrm{PO}_{4}$ that forms the bulk of the substance; its mean particle size is $(6.9 \pm$ 3.9) $\mu \mathrm{m}$.

Figure 4 shows the XRD pattern of the bulk, rhombic dodecahedral, and cubic $\mathrm{Ag}_{3} \mathrm{PO}_{4}$. All diffraction peaks in Figure 4 agree with those of $\mathrm{Ag}_{3} \mathrm{PO}_{4}$ with the standard calorie JPCDS (06-0505). No other impurity peak is observed. Moreover, the full width at half maximum of all diffraction peaks is narrow, indicating purity and good crystallinity of the prepared samples.

3.2. Effect of Morphology on the Chemical Reaction Rate Constant of $\mathrm{Ag}_{3} \mathrm{PO}_{4}$ Micro-/Nanocrystals. Linear regression was 


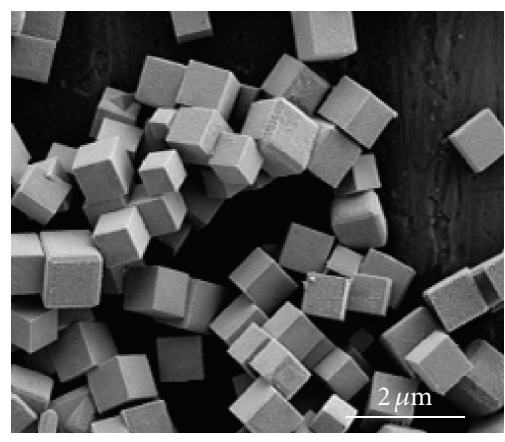

(a)

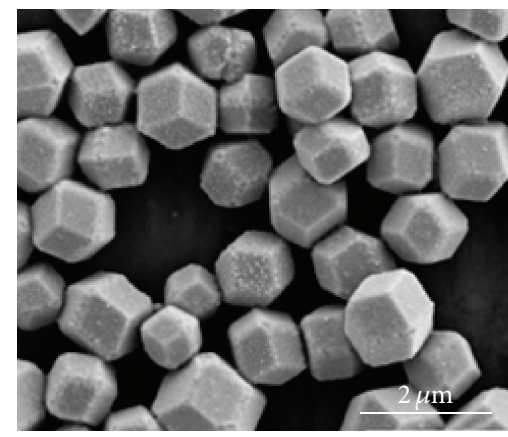

(b)

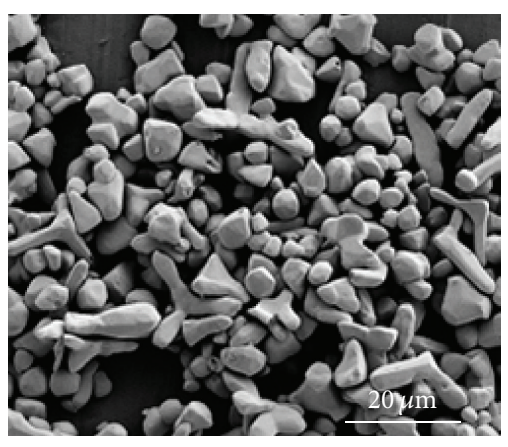

(c)

FIgURE 3: SEM images of cubic (a), rhombic dodecahedral (b), and bulk (c) $\mathrm{Ag}_{3} \mathrm{PO}_{4}$ micro-/nanocrystals.

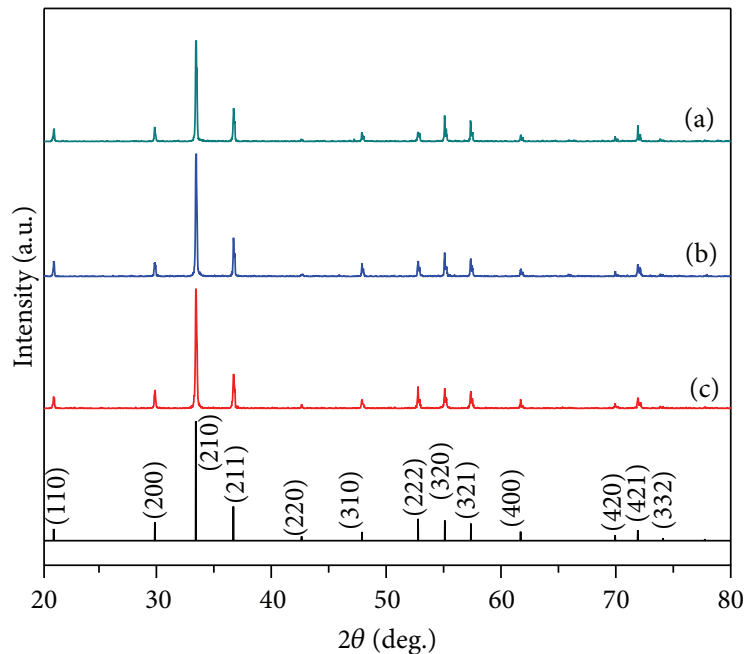

FIGURE 4: XRD patterns of bulk (a), rhombic dodecahedral (b), and cubic (c) $\mathrm{Ag}_{3} \mathrm{PO}_{4}$ micro-/nanocrystals.

performed using the original thermodynamics data obtained from (7), and the reaction rate constants of $\mathrm{Ag}_{3} \mathrm{PO}_{4}$ and $\mathrm{HNO}_{3}$ under varying temperatures were obtained (Table 1).

The curves shown in Figure 5 were drawn on the basis of the reaction rate constants of $\mathrm{Ag}_{3} \mathrm{PO}_{4}$ with $\mathrm{HNO}_{3}$ and the reciprocal of temperature in Table 1.

Figure 5 shows that the reaction rate is proportional to temperature when the particle size is fixed. Compared with bulk $\mathrm{Ag}_{3} \mathrm{PO}_{4}$, the super-refined materials have significantly more particles of the surface phase. Particles of the surface phase account for a large proportion of the total particles. Atoms of the surface phase have uneven stresses, unsaturated force field, and dangling bonds, which lead to high surface energy. This result explains the faster reaction rate of $\mathrm{Ag}_{3} \mathrm{PO}_{4}$ micro-/nanocrystals than bulk $\mathrm{Ag}_{3} \mathrm{PO}_{4}$. As the temperature increases, the surface turbulence and surface energy of $\mathrm{Ag}_{3} \mathrm{PO}_{4}$ micro-/nanocrystals increase; consequently, the chemical reaction increases. The effect of morphology on the reaction rate shows that cubic $\mathrm{Ag}_{3} \mathrm{PO}_{4}$ has higher reaction rate than dodecahedral $\mathrm{Ag}_{3} \mathrm{PO}_{4}$.

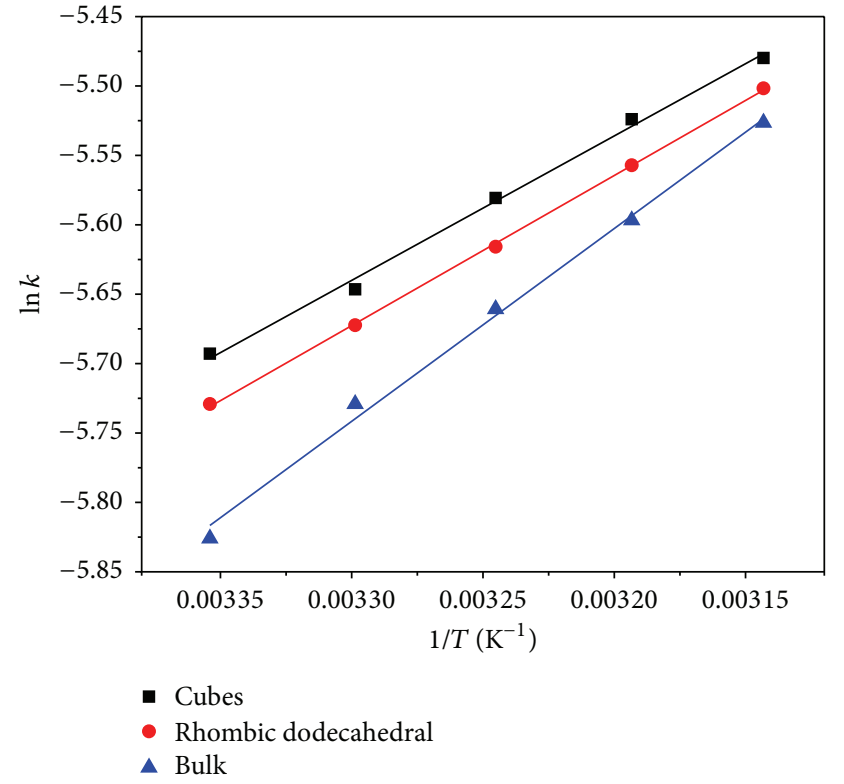

FIGURE 5: Effect of morphology on the reaction rate constant of $\mathrm{Ag}_{3} \mathrm{PO}_{4}$ micro-/nanocrystals with $\mathrm{HNO}_{3}$.

TABLE 1: Reaction rate constant of $\mathrm{Ag}_{3} \mathrm{PO}_{4}$ micro-/nanocrystals with $\mathrm{HNO}_{3}$.

\begin{tabular}{lccccc}
\hline$T(\mathrm{~K})$ & 298.15 & 303.15 & 308.15 & 313.15 & 318.15 \\
\hline$k \cdot 10^{-3}\left(\mathrm{~s}^{-1}\right)$ & & & & & \\
$\quad$ Cube & 3.37 & 3.53 & 3.77 & 3.99 & 4.17 \\
$\quad$ Rhombic dodecahedra & 3.25 & 3.44 & 3.64 & 3.86 & 4.08 \\
Bulk & 2.95 & 3.25 & 3.48 & 3.71 & 3.98 \\
\hline
\end{tabular}

3.3. Effect of Morphology on the Activation Energy, Activation Gibbs Free Energy, Activation Enthalpy, and Activation Entropy of $\mathrm{Ag}_{3} \mathrm{PO}_{4}$ Micro-/Nanocrystals. Linear regression of logarithmic reaction rate constant and temperature reciprocal (slope and intercept in Figure 4) was performed using (8), and the $E_{a}$ of the $\mathrm{Ag}_{3} \mathrm{PO}_{4}$ micro-/nanocrystals reaction was obtained. The $\Delta G_{\neq}^{\theta}$ of the $\mathrm{Ag}_{3} \mathrm{PO}_{4}$ micro-/nanocrystals reaction was calculated using (9). The $\Delta H_{\neq}^{\theta}$ and $\Delta S_{\neq}^{\theta}$ of 
TABLE 2: Activation energy, activation Gibbs free energy, activation enthalpy, and activation entropy of $\mathrm{Ag}_{3} \mathrm{PO}_{4}$ micro-/nanocrystals.

\begin{tabular}{|c|c|c|c|c|c|}
\hline $\begin{array}{l}\mathrm{Ag}_{3} \mathrm{PO}_{4} \\
\text { Micro-/nanocrystals }\end{array}$ & $T(\mathrm{~K})$ & $\Delta G_{\neq}^{\theta}\left(\mathrm{kJ} \cdot \mathrm{mol}^{-1}\right)$ & $E_{a}\left(\mathrm{~kJ} \cdot \mathrm{mol}^{-1}\right)$ & $\Delta H_{\neq}^{\theta}\left(\mathrm{kJ} \cdot \mathrm{mol}^{-1}\right)$ & $\Delta S_{\neq}^{\theta}\left(\mathrm{J} \cdot \mathrm{K}^{-1} \cdot \mathrm{mol}^{-1}\right)$ \\
\hline \multirow{5}{*}{ Cube } & 298.15 & 87.132 & \multirow{5}{*}{8.653} & \multirow{5}{*}{6.093} & \multirow{5}{*}{-271.831} \\
\hline & 303.15 & 88.518 & & & \\
\hline & 308.15 & 89.852 & & & \\
\hline & 313.15 & 91.204 & & & \\
\hline & 318.15 & 92.585 & & & \\
\hline \multirow{5}{*}{$\begin{array}{l}\text { Rhombic } \\
\text { dodecahedra }\end{array}$} & 298.15 & 87.222 & \multirow{5}{*}{8.990} & \multirow{5}{*}{6.430} & \multirow{5}{*}{-270.987} \\
\hline & 303.15 & 88.583 & & & \\
\hline & 308.15 & 89.941 & & & \\
\hline & 313.15 & 91.290 & & & \\
\hline & 318.15 & 92.643 & & & \\
\hline \multirow{5}{*}{ Bulk } & 298.15 & 87.462 & \multirow{5}{*}{11.548} & \multirow{5}{*}{8.988} & \multirow{5}{*}{-263.123} \\
\hline & 303.15 & 88.726 & & & \\
\hline & 308.15 & 90.056 & & & \\
\hline & 313.15 & 91.393 & & & \\
\hline & 318.15 & 92.708 & & & \\
\hline
\end{tabular}

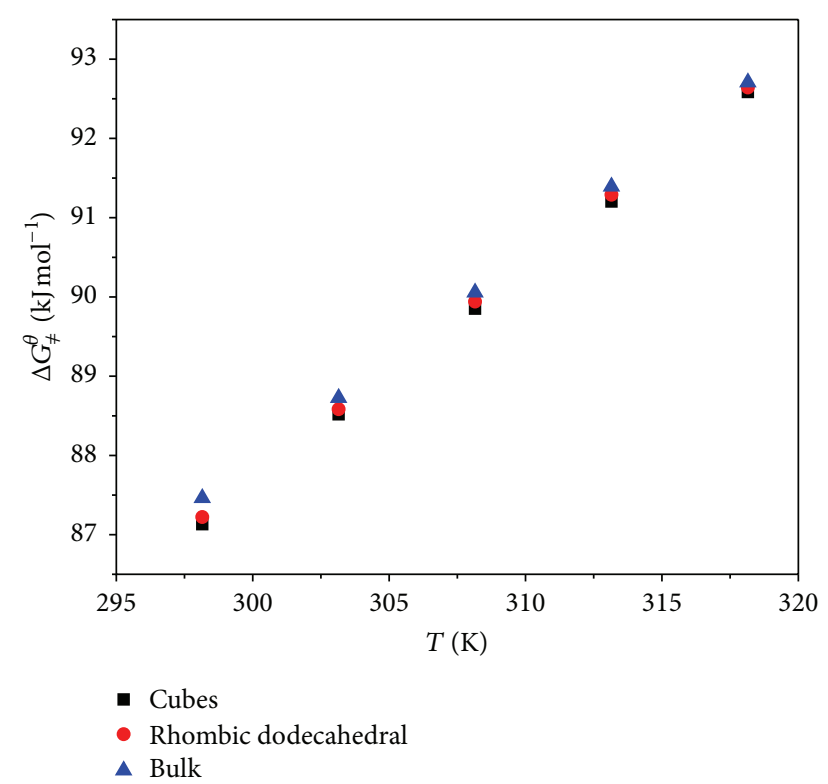

Figure 6: Morphology effect on the activation Gibbs free energy of $\mathrm{Ag}_{3} \mathrm{PO}_{4}$ micro-/nanocrystals.

the $\mathrm{Ag}_{3} \mathrm{PO}_{4}$ micro-/nanocrystals reaction were calculated using (10). Results are listed in Table 2.

As shown in Table 1, the activation energy, activation Gibbs free energy (as shown in Figure 6), activation enthalpy, and activation entropy of $\mathrm{Ag}_{3} \mathrm{PO}_{4}$ micro-/nanocrystals decrease with decreasing particle size. Surface atoms are in metastable state because of the high specific surface effect of micro-/nanomaterials. The nanosystem has higher potential energy than the bulk system because of high specific surface effect. Transition state theory states that the nanosystem has to overcome smaller energy barrier than the bulk system to reach the same transition state. Therefore, smaller particles
TABLE 3: Surface Gibbs free energy of $\mathrm{Ag}_{3} \mathrm{PO}_{4}$ micro-/nanocrystals.

\begin{tabular}{lccccc}
\hline$T(\mathrm{~K})$ & 298.15 & 303.15 & 308.15 & 313.15 & 318.15 \\
\hline$G^{S}\left(\mathrm{~kJ} \cdot \mathrm{mol}^{-1}\right)$ & & & & & \\
$\quad$ Cube & 0.330 & 0.208 & 0.205 & 0.189 & 0.123 \\
$\quad$ Rhombic dodecahedra & 0.240 & 0.143 & 0.115 & 0.103 & 0.066 \\
\hline
\end{tabular}

require less activation energy. The effect of morphology on $E_{a}, \Delta G_{\neq}^{\theta}, \Delta H_{\neq}^{\theta}$, and $\Delta S_{\neq}^{\theta}$ demonstrates that cubic $\mathrm{Ag}_{3} \mathrm{PO}_{4}$ overcomes smaller energy barrier than dodecahedral $\mathrm{Ag}_{3} \mathrm{PO}_{4}$ in the same reaction. Thus, cubic $\mathrm{Ag}_{3} \mathrm{PO}_{4}$ requires less activation energy than dodecahedral $\mathrm{Ag}_{3} \mathrm{PO}_{4}$.

3.4. Effect of Morphology on the Surface Gibbs Free Energy of $\mathrm{Ag}_{3} \mathrm{PO}_{4}$ Micro-/Nanocrystals. Combining (14)-(16), we calculated the surface Gibbs free energy of $\mathrm{Ag}_{3} \mathrm{PO}_{4}$ micro-/ nanocrystals on the basis of the activation Gibbs free energy listed in Table 3.

The molar surface Gibbs free energy of $\mathrm{Ag}_{3} \mathrm{PO}_{4}$ micro-/ nanocrystals $\left(G_{m}^{S}\right)$ under different temperatures is shown in Figure 7. Cubic $\mathrm{Ag}_{3} \mathrm{PO}_{4}$ has higher $G_{m}^{S}$ than rhombic dodecahedral $\mathrm{Ag}_{3} \mathrm{PO}_{4}$. Both conditions are inversely proportional to temperature. The uneven stress on the atoms of the surface phase intensifies with increasing reaction temperature. The thermal motion of nanoparticles also intensifies with the increase in unsaturated force field and dangling bonds. The widening particle space weakens their interaction and decreases the surface tension of nanomaterials, thereby reducing the surface Gibbs free energy.

3.5. Effect of Morphology on the Molar Surface Enthalpy, Molar Surface Entropy, and Molar Surface Energy of $\mathrm{Ag}_{3} \mathrm{PO}_{4}$ Micro-/Nanocrystals. The $H_{m}^{S}, S_{m}^{S}$, and $E_{m}^{S}$ of $\mathrm{Ag}_{3} \mathrm{PO}_{4}$ micro-l nanocrystals were calculated using (17), (18), and (19), respectively. 
TABLE 4: Morphology effect on the surface enthalpy, surface entropy, and surface energy of $\mathrm{Ag}_{3} \mathrm{PO}_{4}$ micro-/nanocrystals.

\begin{tabular}{llc}
\hline Surface energies & \multicolumn{2}{c}{$\mathrm{Ag}_{3} \mathrm{PO}_{4}$ micro-/nanocrystals } \\
& Cube & Rhombic dodecahedron \\
\hline$H_{m}^{S}\left(\mathrm{~kJ} \cdot \mathrm{mol}^{-1}\right)$ & 2.895 & 2.558 \\
$S_{m}^{S}\left(\mathrm{~kJ} \cdot \mathrm{mol}^{-1}\right)$ & 8.708 & 7.864 \\
$E_{m}^{S}\left(\mathrm{~kJ} \cdot \mathrm{mol}^{-1}\right)$ & 2.895 & 2.558 \\
\hline
\end{tabular}

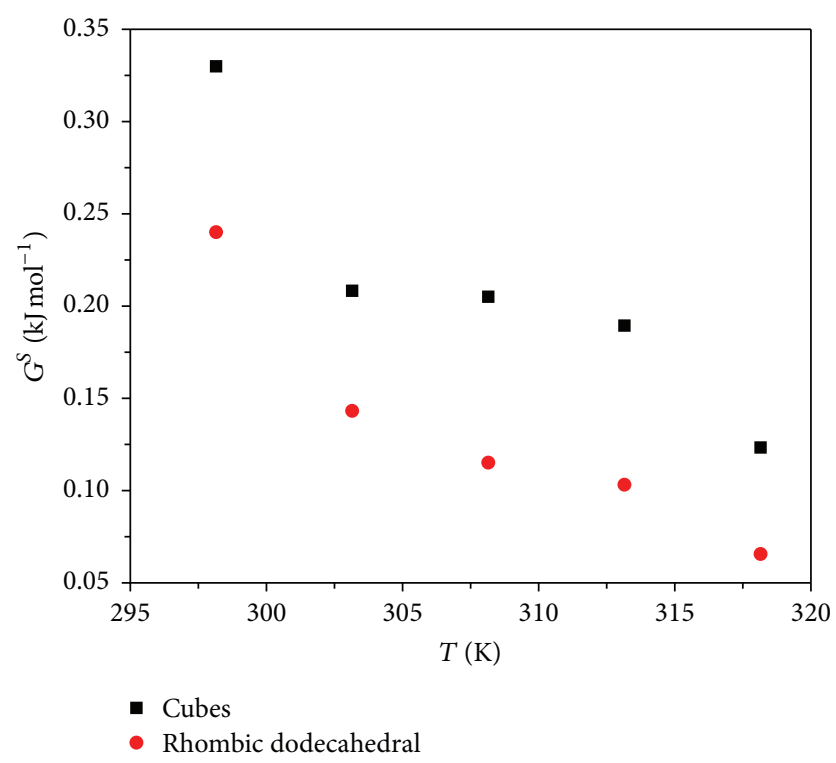

FIGURE 7: Morphology effect on surface Gibbs free energy of $\mathrm{Ag}_{3} \mathrm{PO}_{4}$ micro-/nanocrystals.

Table 4 shows that cubic $\mathrm{Ag}_{3} \mathrm{PO}_{4}$ micro-/nanocrystals have higher $H_{m}^{S}, S_{m}^{S}$, and $E_{m}^{S}$ than rhombic dodecahedral $\mathrm{Ag}_{3} \mathrm{PO}_{4}$. This result agrees with that on surface Gibbs free energy. Molar surface energy is the sum of the kinetic energy, potential energy, and chemical energy of surface phase particles. After super-refinement of the material, atoms of the surface phase suffer from uneven stress, display unsaturated force field, and possess dangling bonds because of strong specific surface effect. Consequently, the interaction of nanoparticles is enhanced. This phenomenon explains why micro-/nanomaterials have high kinetic energy and potential energy.

\section{Conclusion}

This study determined the surface energies of $\mathrm{Ag}_{3} \mathrm{PO}_{4}$ micro/nanocrystals and their kinetic parameters when reacting with $\mathrm{HNO}_{3}$ by using microcalorimetry. It also discussed rationally combined thermochemical cycle, transition state theory, basic theory of chemical thermodynamics with thermokinetic principle, morphology dependence of reaction kinetics, and surface thermodynamic properties. Results show that the molar surface enthalpy, molar surface entropy, molar surface Gibbs free energy, and molar surface energy of cubic $\mathrm{Ag}_{3} \mathrm{PO}_{4}$ micro-/nanocrystals are larger than those of rhombic dodecahedral $\mathrm{Ag}_{3} \mathrm{PO}_{4}$ micro-/nanocrystals. Compared with rhombic dodecahedral $\mathrm{Ag}_{3} \mathrm{PO}_{4}$, cubic $\mathrm{Ag}_{3} \mathrm{PO}_{4}$ with high surface energy exhibits higher reaction rate and lower activation energy, activation Gibbs free energy, activation enthalpy, and activation entropy. These results indicate that cubic $\mathrm{Ag}_{3} \mathrm{PO}_{4}$ micro-/nanocrystals possess a much higher reactivity and it is more easily activated than rhombic dodecahedral $\mathrm{Ag}_{3} \mathrm{PO}_{4}$ micro-/nanocrystals. This paper presents a novel facile approach to study the surface thermodynamic property of nanomaterials and the structurefunction relationship between reaction dynamics and size, morphology, and structure.

\section{Conflict of Interests}

The authors declare that there is no conflict of interests regarding the publication of this paper.

\section{Acknowledgments}

The authors are thankful for the financial support from the National Natural Science Foundation of China (21273050, 21573048), high level innovation teams and academic excellence scheme of colleges and universities in Guangxi (Guangxi teach [2014]7), the Reform of Postgraduate Cultivation Mechanism from 2013 (Chemical Engineering, 113000100030001), and Innovation Projects of Postgraduate Education of Guangxi University for Nationalities (gxunchxs2015086). The authors would like to express their great appreciation to Guangxi Colleges and Universities Key Laboratory of Food Safety and Pharmaceutical Analytical Chemistry (Guangxi University for Nationalities).

\section{References}

[1] L. D. Zhang, The Preparation and Application of Superfine Powders, China Petrochemical Press, Beijing, China, 2001.

[2] L. D. Zhang and J. M. Mou, Nanomaterials and Nanostructures, Science Press, Beijing, China, 2001.

[3] J. Du, R. Zhao, and Y. Q. Xue, "Effects of sizes of nanocopper oxide on the equilibrium constant and thermodynamic properties for the reaction in nanosystem," Journal of Chemical Thermodynamics, vol. 45, no. 1, pp. 48-52, 2012.

[4] Y. Q. Xue, B. J. Gao, and J. F. Gao, "The theory of thermodynamics for chemical reactions in dispersed heterogeneous systems," Journal of Colloid and Interface Science, vol. 191, no. 1, pp. 81-85, 1997.

[5] J. P. Du, H. Y. Wang, and R. H. Zhao, "Size-dependent thermodynamic properties and equilibrium constant of chemical reaction in nanosystem: an experimental study (II)," Journal of Chemical Thermodynamics, vol. 65, pp. 29-33, 2013.

[6] L. Mazeina, S. Deore, and A. Navrotsky, "Energetics of bulk and nano-akaganeite, $\beta$-FeOOH: enthalpy of formation, surface enthalpy, and enthalpy of water adsorption," Chemistry of Materials, vol. 18, no. 7, pp. 1830-1838, 2006.

[7] L. Mazeina and A. Navrotsky, "Enthalpy of water adsorption and surface enthalpy of goethite $(\alpha-\mathrm{FeOOH})$ and hematite $(\alpha$ $\mathrm{Fe}_{2} \mathrm{O}_{3}$ )," Chemistry of Materials, vol. 19, no. 4, pp. 825-833, 2007.

[8] X. X. Li, Z. Y. Huang, L. Y. Zhong, T. H. Wang, and X. C. Tan, "Size effect on reaction kinetics and surface thermodynamic 
properties of nano-octahedral cadmium molybdate," Chinese Science Bulletin, vol. 59, pp. 2490-2498, 2014.

[9] T. H. Wang, L. D. Wang, Y. X. Guo, Y. F. Li, G. C. Fan, and Z. Y. Huang, "Standard molar enthalpy of formation of uniform $\mathrm{CdMoO}_{4}$ nano-octahedra," Chinese Science Bulletin, vol. 58, no. 26, pp. 3208-3212, 2013.

[10] D. Fernández-Cañoto and J. Z. Larese, “Thermodynamic and modeling study of thin n-heptane films adsorbed on magnesium oxide (100) surfaces," The Journal of Physical Chemistry C, vol. 118, no. 7, pp. 3451-3458, 2014.

[11] Z.-Y. Zhou, N. Tian, J.-T. Li, I. Broadwell, and S.-G. Sun, "Nanomaterials of high surface energy with exceptional properties in catalysis and energy storage," Chemical Society Reviews, vol. 40, no. 7, pp. 4167-4185, 2011.

[12] Q. Kuang, X. Wang, Z. Jiang, Z. Xie, and L. Zheng, "Highenergy-surface engineered metal oxide micro- and nanocrystallites and their applications," Accounts of Chemical Research, vol. 47, no. 2, pp. 308-318, 2014.

[13] L. H. Hu, Q. Peng, and Y. Li, "Selective synthesis of $\mathrm{Co}_{3} \mathrm{O}_{4}$ nanocrystal with different shape and crystal plane effect on catalytic property for methane combustion," Journal of the American Chemical Society, vol. 130, no. 48, pp. 16136-16137, 2008.

[14] Y.-Z. Wen, Y.-Q. Xue, Z.-X. Cui, and Y. Wang, "Thermodynamics of nanoadsorption from solution: theoretical and experimental research," Journal of Chemical Thermodynamics, vol. 80, pp. 112-118, 2014.

[15] Z.-X. Cui, M.-Z. Zhao, W.-P. Lai, and Y.-Q. Xue, "Thermodynamics of size effect on phase transition temperatures of dispersed phases," Journal of Physical Chemistry C, vol. 115, no. 46, pp. 22796-22803, 2011.

[16] Y. Yunfeng, X. Yongqiang, C. Zixiang, and Z. Miaozhi, "Effect of particle size on electrode potential and thermodynamics of nanoparticles electrode in theory and experiment," Electrochimica Acta, vol. 136, pp. 565-571, 2014.

[17] B. Slater, C. Richard, A. Catlow, D. H. Gay, D. E. Williams, and V. Dusastre, "Study of surface segregation of antimony on $\mathrm{SnO}_{2}$ surfaces by computer simulation techniques," Journal of Physical Chemistry B, vol. 103, no. 48, pp. 10644-10650, 1999.

[18] M. Lazzeri, A. Vittadini, and A. Selloni, "Structure and energetics of stoichiometric $\mathrm{TiO}_{2}$ anatase surfaces," Physica B: Condensed Matter, vol. 63, no. 15, Article ID 155409, 2001.

[19] M. Lazzeri, A. Vittadini, and A. Selloni, "Erratum: structure and energetics of stoichiometric $\mathrm{TiO}_{2}$ anatase surfaces," Physical Review B: Condensed Matter, vol. 65, Article ID 119901, 2002.

[20] J. M. McHale, A. Auroux, A. J. Perrotta, and A. Navrotsky, "Surface energies and thermodynamic phase stability in nanocrystalline aluminas," Science, vol. 277, no. 5327, pp. 788789, 1997.

[21] A. V. Radha, O. Bomati-Miguel, S. V. Ushakov, A. Navrotsky, and P. Tartaj, "Surface enthalpy, enthalpy of water adsorption, and phase stability in nanocrystalline monoclinic zirconia," Journal of the American Ceramic Society, vol. 92, no. 1, pp. 133140, 2009.

[22] M. K. Chaudhury and G. M. Whitesides, "Correlation between surface free energy and surface constitution," Science, vol. 255, no. 5049, pp. 1230-1232, 1992.

[23] K. Kendall, N. M. Alford, and J. D. Birchall, "A new method for measuring the surface energy of solids," Nature, vol. 325, no. 6107, pp. 794-796, 1987.
[24] V. M. Huxter, A. Lee, S. S. Lo, and G. D. Scholes, "CdSe nanoparticle elasticity and surface energy," Nano Letters, vol. 9, no. 1, pp. 405-409, 2009.

[25] Q. Wu, M. Liu, Z. Wu, Y. Li, and L. Piao, "Is photooxidation activity of 001 facets truly lower than that of 101 facets for anatase $\mathrm{TiO}_{2}$ crystals?" The Journal of Physical Chemistry C, vol. 116, no. 51, pp. 26800-26804, 2012.

[26] W. H. Luo, Molecular dynamic calculation of free energy and its application in nanostructured materials [Ph.D. thesis], Hunan University, Changsha, China, 2008.

[27] G. A. Hulett, "The solubility of gypsum as affected by size of particles and by different crystal-lographic surfaces," Journal of the American Chemical Society, vol. 27, no. 1, pp. 49-56, 1995.

[28] W. J. Jones, "Uber die beziehung zwischen geometrischer form und dampfdruck, löslichkeit, und formenstabilität," Annalen der Physik, vol. 346, no. 7, pp. 441-448, 1913.

[29] R. K. Tang, G. H. Nancollas, and C. A. Orme, "Mechanism of dissolution of sparingly soluble electrolytes," Journal of the American Chemical Society, vol. 123, no. 23, pp. 5437-5443, 2001.

[30] R. K. Tang, L. Wang, C. A. Orme, T. Bonstein, P. J. Bush, and G. H. Nancollas, "Dissolution at the nanoscale: self-preservation of biominerals," Angewandte Chemie, vol. 43, no. 20, pp. 26972701, 2004

[31] R. Tang, W. Wu, M. Haas, and G. H. Nancollas, "Kinetics of dissolution of $\beta$-tricalcium phosphate," Langmuir, vol. 17, no. 11, pp. 3480-3485, 2001.

[32] R. K. Tang, "Progress in the studies of interfacial energy and kinetics of crystal growth/dissolution," Progress in Chemistry, vol. 17, no. 2, pp. 369-376, 2005.

[33] V. K. Kumikov and K. B. Khokonov, "On the measurement of surface free energy and surface tension of solid metals," Journal of Applied Physics, vol. 54, no. 3, pp. 1346-1350, 1983.

[34] H. P. Bonzel and M. Nowicki, "Absolute surface free energies of perfect low-index orientations of metals and semiconductors," Physical Review B, vol. 70, no. 24, Article ID 245430, 2004.

[35] H. P. Bonzel and A. Emundts, "Absolute values of surface and step free energies from equilibrium crystal shapes," Physical Review Letters, vol. 84, no. 25, pp. 5804-5807, 2000.

[36] Z. Yi, J. Ye, N. Kikugawa et al., "An orthophosphate semiconductor with photooxidation properties under visible-light irradiation," Nature Materials, vol. 9, no. 7, pp. 559-564, 2010.

[37] Y. Bi, H. Hu, S. Ouyang, G. Lu, J. Cao, and J. Ye, "Photocatalytic and photoelectric properties of cubic $\mathrm{Ag}_{3} \mathrm{PO}_{4}$ submicrocrystals with sharp corners and edges," Chemical Communications, vol. 48, no. 31, pp. 3748-3750, 2012.

[38] Z. Jiao, Y. Zhang, H. Yu, G. Lu, J. Ye, and Y. Bi, "Concave trisoctahedral $\mathrm{Ag}_{3} \mathrm{PO}_{4}$ microcrystals with high-index facets and enhanced photocatalytic properties," Chemical Communications, vol. 49, no. 6, pp. 636-638, 2013.

[39] Y. Bi, S. Ouyang, N. Umezawa, J. Cao, and J. Ye, "Facet effect of single-crystalline $\mathrm{Ag}_{3} \mathrm{PO}_{4}$ sub-microcrystals on photocatalytic properties," Journal of the American Chemical Society, vol. 133, no. 17, pp. 6490-6492, 2011.

[40] Z. J. Liu, G. C. Fan, and Z. Y. Huang, "Catalytic process thermodynamics, kinetics and surface thermodynamic effect of different morphologies $\mathrm{Ag}_{3} \mathrm{PO}_{4}$," Science in China Series B: Chemistry, vol. 45, no. 8, pp. 855-862, 2015.

[41] R. Rychlý and V. Pekárek, "The use of potassium chloride and tris (hydroxymethyl) aminomethane as standard substances for solution calorimetry," The Journal of Chemical Thermodynamics, vol. 9, no. 4, pp. 391-396, 1977. 
[42] Y.-Q. Xue, J.-P. Du, P.-D. Wang, and Z.-Z. Wang, "Effect of particle size on kinetic parameters of the heterogeneous reactions," Acta Physico-Chimica Sinica, vol. 21, no. 7, pp. 758762,2005

[43] Y. Q. Xue, Effects of particle size on phase transitions and reactions of nanosystems [Ph.D. thesis], Taiyuan University of Technology, Taiyuan, China, 2005.

[44] R. Z. Hu, Q. F. Zhao, and H. X. Gao, Calorimetry Fundamentals and Application, Science Press, Beijing, China, 2011.

[45] L. D. Wang, S. G. Liu, X. L. Liu, Z. J. Liu, Z. Ma, and Z. Y. Huang, "Thermodynamic functions and growth constants of web-like ZnO nanostructures," Chinese Science Bulletin, vol. 58, no. 27, pp. 3380-3384, 2013. 

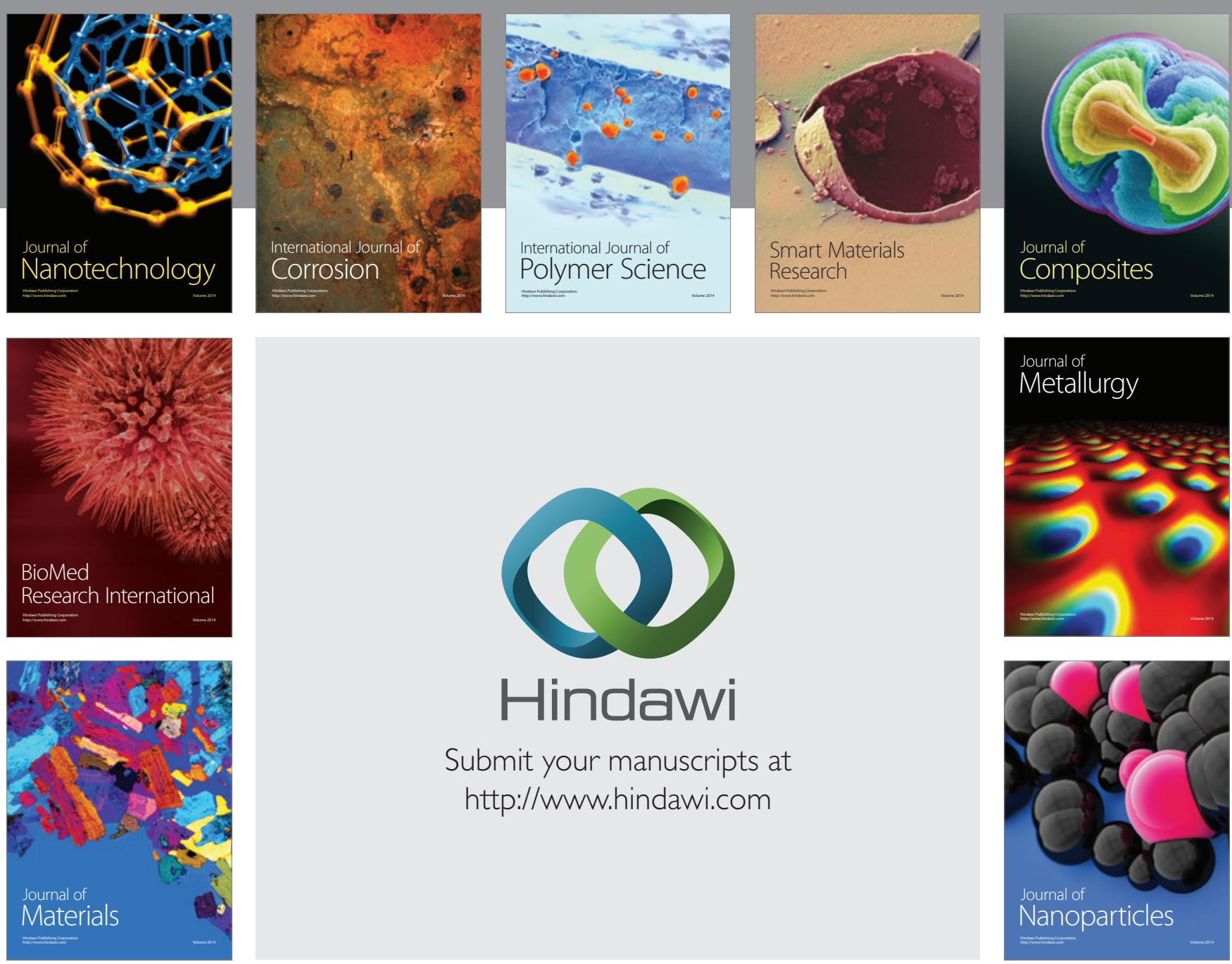

Submit your manuscripts at http://www.hindawi.com
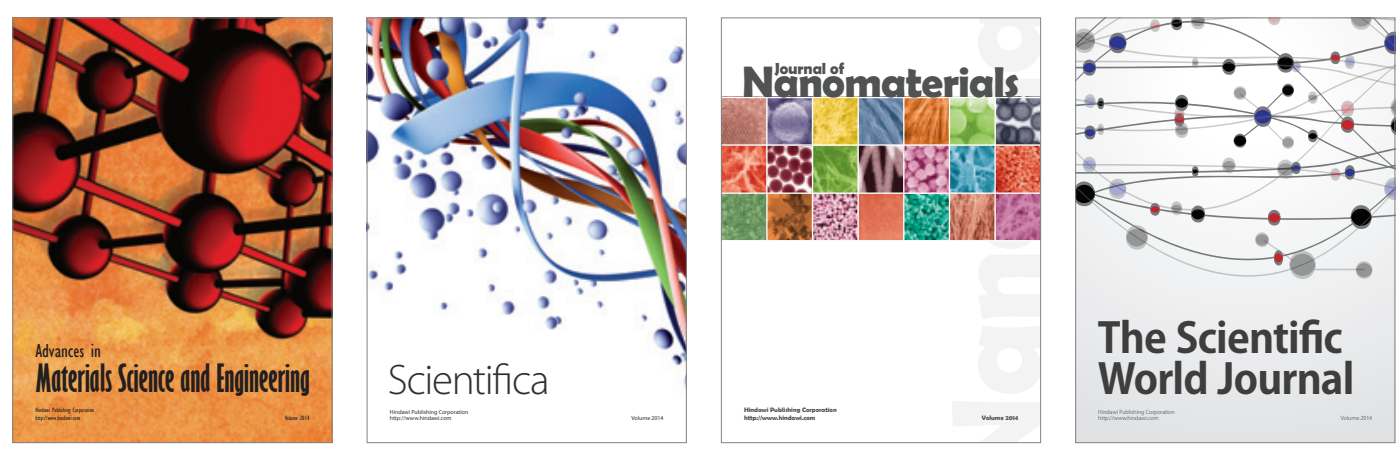

\section{The Scientific World Journal}
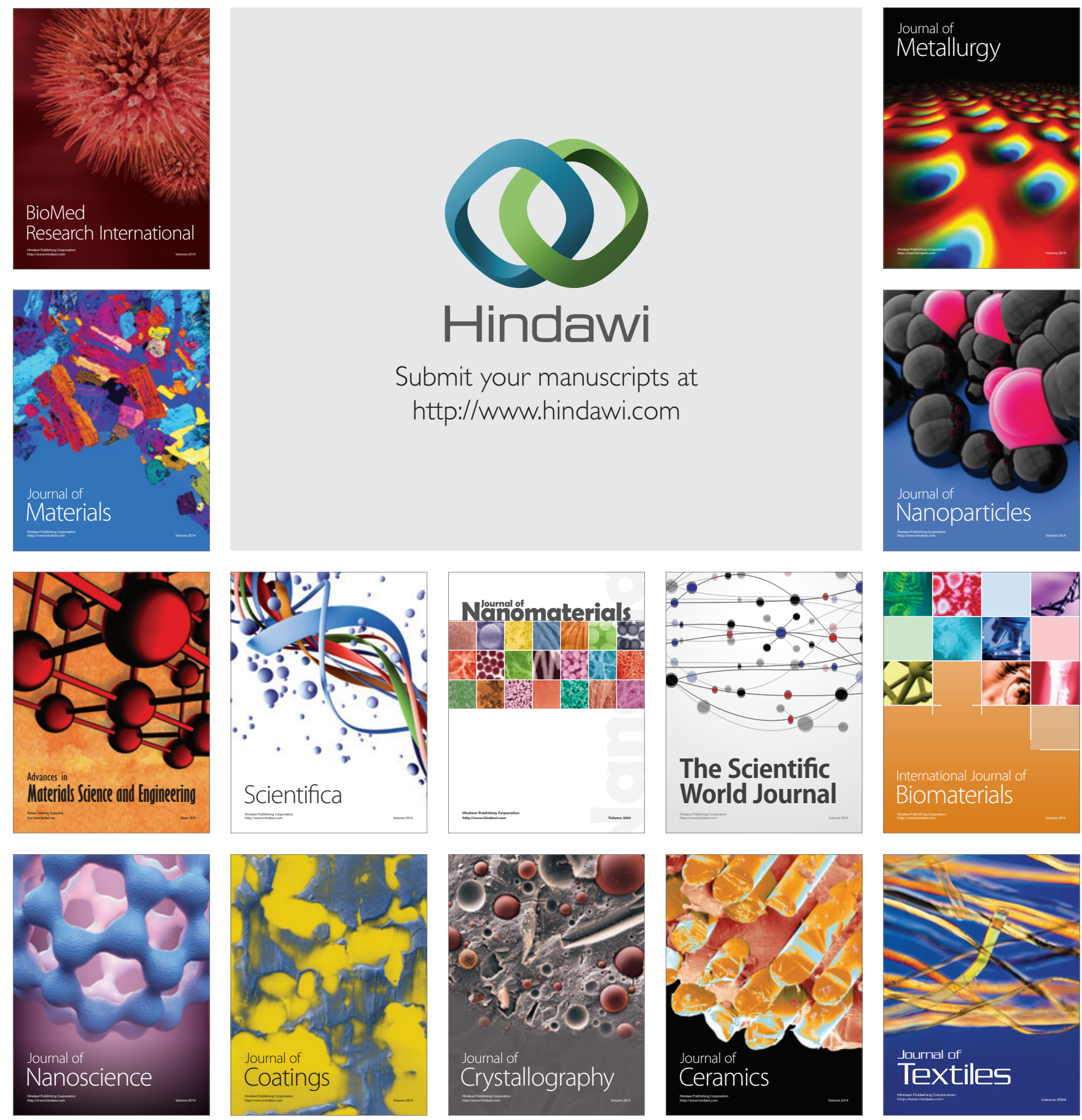